\title{
MATHEMATICAL MODELLING AND PREDICTION OF CONGO RED ADSORPTION ON CHERRY STONES ACTIVATED CARBON
}

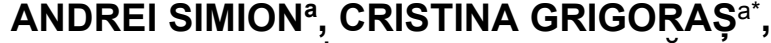 \\ LIDIA FAVIER ${ }^{b}$, LUCIAN GAVRILĂ ${ }^{a^{*}}$
}

\begin{abstract}
The present paper was aimed to establish mathematical models useful to reduce the time required to discover the appropriate adsorption conditions of Congo Red (an intensively used organic dye) on an activated carbon prepared from cherry stones through calcination. To this purpose, various values of three parameters known as influencing the process, namely dye initial concentration ( $200 \mathrm{mg} / \mathrm{L}$ to $1000 \mathrm{mg} / \mathrm{L}$ ), $\mathrm{pH}$ (2 to 12) and contact time (10 to 180 minutes) between the adsorbent and the adsorbate were variated. The recorded results of the adsorption process were used as data for Response Surface Methodology and Artificial Neural Network and several mathematical equations were generated. The conducted statistical analyses revealed that these equations can accurately express the Congo Red elimination from aqueous solutions. Moreover, the developed procedure is able to predict the process evolution in different conditions than those experimentally tested.
\end{abstract}

Keywords: Adsorption, Artificial Neural Network, cherry stone, Congo Red, mathematical modelling, Response Surface Methodology, water treatment

\section{INTRODUCTION}

Colored wastewater coming from various industries is considered a major source of environmental concerns. Besides being responsible for the unwanted visual effect, due to their chemical structures, dyes are often characterized by a reduced biodegradability being difficult to remove by classical wastewater treatments [1]. Moreover, most of the dyes can also negatively affect

a "Vasile Alecsandri" University of Bacău; Faculty of Engineering; Department of Food and Chemical Engineering; Calea Mărășești 157, RO-600115, Bacău, România

b Univ. Rennes, Ecole Nationale Supérieure de Chimie de Rennes; CNRS, UMR 6226; 11 Allée de Beaulieu, CS 50837, 35708 Rennes Cedex 7, France

*Corresponding authors: cristina.grigoras@ub.ro, Igavrila@ub.ro 
the human and animals state of health causing severe skin irritations [2, 3], respiratory problems [4], liver damages or central nervous system injuries [5].

Therefore, many procedures directed to treat dye containing effluents are tested and the interest in developing and adapting other techniques increases continuously.

One of these methods is represented by the adsorption process. Recognized as an efficient, inexpensive and simple to manage procedure [6], the adsorption can be conducted even by using low cost materials such as biomass prepared from flower spikes [7], alginate [8], chitosan [9, 10], clays [11, 12] composites [13-15], adsorbents obtained from vegetal wastes [16, 17] including olive cake [18], date wastes [19], seeds [20], coffee grounds [21] etc.

The adsorption mechanism relies on different interactions (van der Waals forces, hydrogen bonding, polarity, static interactions, dipole-dipole interactions etc.) occurring between the adsorbent and the adsorbate [22] and on the chemical attractions taking place between them [23]. Its efficiency is strongly influenced by a series of factors related to dye (class type, molecular structure etc.), characteristics of the material possessing adsorbing properties (surface area, regenerating capacity etc.) and to the parameters affecting the process (dye solution $\mathrm{pH}$, its initial concentration, temperature, length of the contact time, adsorbent amount - dye solution volume ratio etc.). These aspects have been the subject of many researches [24-27] which revealed that dyes adsorption represent a very attractive alternative to the costlier other techniques of wastewater treatment [28-30] such as those employing for example immobilized enzymes [31], nanofiltration [32], Fenton oxidation [33], photosynthetic bacteria [34] or biogenic nanomaterials [35]. The already conducted investigations show also that the steps to be followed for establishing the appropriate dye adsorption conditions are time-consuming and require multiple experimental tests.

Based on these considerations, in this work, we have used an absorbent material obtained from cherry stones (CS) by physical activation to eliminate Congo Red (CR) (a frequent anionic azo dye in textile, paper, cosmetic, printing industries) from aqueous solutions. The effect of $\mathrm{pH}$, dye initial concentration and contact time was primarily explored. Then, the acquired data were introduced in computer specific software. Mathematical modeling and simulation were tested for predicting the adequate parameters to be utilized in order to obtain the best results in terms of CR removal. Two different approaches: the Response Surface Methodology (RSM) and the Artificial Neural Network (ANN) were applied. Their choice was based on the fact that they have been reported as procuring precise results for dye adsorption modeling. RSM takes into account the interactions of the involved parameters being helpful for designing the experiments. It fits linear or polynomial functions to the collected data [3638]. ANN is known as a simple and highly reliable artificial intelligence technique which can connect large sets of variables with the purpose of offering trustful nonlinear mathematical equations $[39,40]$. Both methodologies return models verified by statistical tests $[41,42]$. 
MATHEMATICAL MODELLING AND PREDICTION OF CONGO RED ADSORPTION ON CHERRY STONES ACTIVATED CARBON

\section{RESULTS AND DISCUSSION}

\section{Congo Red adsorption process onto cherry stones activated carbon}

Table 1. Congo Red dye final concentrations after adsorption on cherry stones activated carbon in different working conditions

\begin{tabular}{|c|c|c|c|c|c|}
\hline $\begin{array}{c}\text { Initial dye } \\
\text { concentration }\end{array}$ & $200 \mathrm{mg} / \mathrm{L}$ & $400 \mathrm{mg} / \mathrm{L}$ & $600 \mathrm{mg} / \mathrm{L}$ & $800 \mathrm{mg} / \mathrm{L}$ & $1000 \mathrm{mg} / \mathrm{L}$ \\
\hline Time (min) & \multicolumn{5}{|c|}{ Final dye concentration $(\mathrm{mg} / \mathrm{L})$ at $\mathrm{pH} 2$} \\
\hline 10 & 11.172 & 20.007 & 26.994 & 39.812 & 55.184 \\
\hline 20 & 5.858 & 7.591 & 16.007 & 27.044 & 37.148 \\
\hline 30 & 3.578 & 5.448 & 8.333 & 15.628 & 18.621 \\
\hline 40 & 2.022 & 3.612 & 5.757 & 7.911 & 8.788 \\
\hline 55 & 1.075 & 2.336 & 3.212 & 4.911 & 6.012 \\
\hline 60 & 0.827 & 1.272 & 1.896 & 2.435 & 3.312 \\
\hline 80 & 0.803 & 1.146 & 1.728 & 2.045 & 2.873 \\
\hline 90 & 0.791 & 1.083 & 1.644 & 1.850 & 2.654 \\
\hline 100 & 0.738 & 1.018 & 1.526 & 1.807 & 2.496 \\
\hline 120 & 0.631 & 0.888 & 1.290 & 1.722 & 2.181 \\
\hline 150 & 0.588 & 0.833 & 1.272 & 1.678 & 2.109 \\
\hline 180 & 0.488 & 0.779 & 1.178 & 1.622 & 1.899 \\
\hline Time (min) & \multicolumn{5}{|c|}{ Final dye concentration $(\mathrm{mg} / \mathrm{L})$ at $\mathrm{pH} 4.5$} \\
\hline 10 & 18.177 & 29.580 & 43.797 & 60.602 & 78.919 \\
\hline 20 & 11.031 & 19.930 & 30.755 & 45.305 & 57.978 \\
\hline 30 & 8.390 & 14.616 & 20.745 & 31.961 & 42.375 \\
\hline 40 & 5.503 & 9.100 & 13.129 & 20.372 & 25.439 \\
\hline 55 & 3.575 & 4.879 & 6.873 & 10.133 & 13.208 \\
\hline 60 & 1.822 & 2.112 & 2.913 & 4.054 & 5.251 \\
\hline 80 & 1.436 & 1.870 & 2.686 & 3.519 & 4.946 \\
\hline 90 & 1.243 & 1.750 & 2.572 & 3.251 & 4.794 \\
\hline 100 & 1.210 & 1.677 & 2.441 & 3.111 & 4.684 \\
\hline 120 & 1.144 & 1.531 & 2.179 & 2.832 & 4.464 \\
\hline 150 & 0.891 & 1.169 & 1.705 & 2.599 & 3.693 \\
\hline 180 & 0.594 & 1.052 & 1.607 & 1.998 & 2.500 \\
\hline Time (min) & \multicolumn{5}{|c|}{ Final dye concentration $(\mathrm{mg} / \mathrm{L})$ at $\mathrm{pH} 7$} \\
\hline 10 & 29.782 & 40.271 & 57.168 & 71.181 & 90.788 \\
\hline 20 & 20.181 & 30.123 & 40.01 & 52.571 & 70.644 \\
\hline 30 & 11.746 & 18.205 & 30.25 & 41.200 & 54.707 \\
\hline 40 & 7.101 & 13.137 & 20.274 & 29.786 & 37.331 \\
\hline 55 & 5.588 & 8.370 & 10.774 & 15.333 & 21.58 \\
\hline 60 & 2.474 & 3.273 & 4.662 & 6.970 & 7.981 \\
\hline 80 & 2.050 & 2.676 & 4.153 & 5.690 & 6.823 \\
\hline 90 & 1.838 & 2.377 & 3.899 & 5.050 & 6.244 \\
\hline 100 & 1.628 & 2.298 & 3.819 & 4.928 & 6.014 \\
\hline 120 & 1.207 & 2.141 & 3.660 & 4.683 & 5.555 \\
\hline 150 & 0.599 & 1.216 & 2.638 & 4.282 & 5.350 \\
\hline 180 & 0.516 & 1.178 & 2.452 & 3.500 & 4.210 \\
\hline
\end{tabular}


The results of the adsorption process of Congo Red dye on activated carbon prepared from the cherry stones are represented in Table 1. For all the initial concentrations tested in the experiments, more than $90 \%$ of the pollutant was retained after only 10 minutes of contact between the adsorbent material and the dye solutions. After 180 minutes the adsorption efficiency reached over $99 \%$. Similar observations were reported by other researches which have studied the CR elimination from aqueous effluents by the help of different adsorbing materials made from biowastes [43] or wood sawdust [44]. These researches explain that $\mathrm{CR}$ exists in its cationic form at acidic $\mathrm{pH}$. The experiments showed that a $\mathrm{pH}$ between 2 and 7 favors the adsorption. Therefore, it can be concluded that the adsorbent surface is able to retain the pollutant due to the electrostatic attraction caused by its positively charged surface. On the contrary, when the experimental program was conduced at higher $p \mathrm{H}$ (10 and 12) (data not shown here) a very low CR retention was observed confirming the above hypothesis since at alkaline $\mathrm{pHCR}$ is in anionic form. In this case, $\mathrm{HSO}_{3}{ }^{-}$ion will turn into $-\mathrm{SO}^{3}-\mathrm{Na}^{+}$. As consequence, the $\mathrm{CR}$ negative charge density will decrease inducing an electrostatic repulsion between the pollutant and the adsorbent surface with unfavorable repercussions on the adsorption process.

\section{RSM modelling}

\section{Models fitting}

As stated before, RSM is a powerful tool containing multiple designs. The most frequently employed ones, Central composite and Box-Behnken, present limitations in considering the extent of the investigation ranges and/or the inability of including key experimental extreme points. Moreover, the generated equations present unsatisfactory correlation coefficients (with rather reduced values). Due to these facts and in order to characterize the entire adsorption process, it seemed adequate to create a custom central composite design (CCCD). Therefore, a three-factors with three variation levels CCCD consisting of 135 experimental runs (data not showed but retrieved from Table 1), including replications at the center point, was adopted to optimize the experimental data. The response function (the final CR concentration) was expressed by the linear and polynomial equations (1), (2) and (3).

$$
\begin{array}{ll}
\text { Linear } & Y=13.9211+9.622351 A+5.094307 B-19.0636 C(1) \\
\text { Quadratic } & Y=5.523482+9.157365 A+5.690574 B-19.5703 C+ \\
& 3.011641 A B-12.5546 A C-6.83729 B C+1.826601 A^{2}- \\
& 0.849685 B^{2}+18.124092 C^{2}(2)
\end{array}
$$


MATHEMATICAL MODELLING AND PREDICTION OF CONGO RED ADSORPTION ON CHERRY STONES ACTIVATED CARBON

$$
\begin{array}{ll}
\text { Cubic } \quad & Y=5.808814+5.542864 A+3.895732 B-15.1419 C+ \\
& 2.908154 A B-12.8594 A C-6.94087 B C+1.73932 A^{2}- \\
& 0.79793 B^{2}+17.91289 C^{2}-2.79414 A B C+0.298217 A^{2} B- \\
& 2.35658 A^{2} C-1.14011 A B^{2}+10.96966 A C^{2}+1.397214 B^{2} C+ \\
& 3.728796 B C^{2}-0.54938 A^{3}-5.6188 C^{3}(3)
\end{array}
$$

where $Y$ represent the final dye concentration and $A, B$ and $C$ are the coded values of the initial dye concentration, $\mathrm{pH}$ and adsorption time, respectively.

The sequential model sum of squares (Table 2) can be viewed in the reduction of the sum of squares error (SSE). A predictor added to a model explains some of the response variability and thereby reduces the error. A sequential sum of squares quantifies how much variability could be explained (increase in regression sum of squares) or alternatively how much error could be reduced (reduction in the error sum of squares). In this study, the sequential model shows a value of 1648.202 for the sum of squares and therefore it favors the selection of the cubic polynomial equation instead of the quadratic model even though this last one is intensively used when RSM is applied.

Table 2. Sequential model sum of squares

\begin{tabular}{|l|l|l|l|l|l|}
\hline \multicolumn{1}{|c|}{ Model } & \multicolumn{1}{|c|}{$\begin{array}{c}\text { Sum of } \\
\text { Squares }\end{array}$} & $\begin{array}{c}\text { Degree of } \\
\text { freedom }\end{array}$ & $\begin{array}{c}\text { Mean } \\
\text { Square }\end{array}$ & F-value & $\begin{array}{c}\text { p-value } \\
\text { Prob > F }\end{array}$ \\
\hline Mean vs Total & 28883.77 & 1 & 28883.77 & - & - \\
\hline Linear vs Mean & 30965.47 & 3 & 10321.82 & 90.34611 & $<0.0001$ \\
\hline 2FI* vs Linear & 6925.197 & 3 & 2308.399 & 36.74498 & $<0.0001$ \\
\hline Quadratic vs 2FI & 6024.829 & 3 & 2008.276 & 124.4959 & $<0.0001$ \\
\hline Cubic vs Quadratic & 1648.202 & 9 & 183.1336 & 57.69459 & $<0.0001$ \\
\hline Residual & 368.2059 & 116 & 3.174189 & - & - \\
\hline Total & 74815.68 & 135 & 554.1902 & - & - \\
\hline
\end{tabular}

*2FI - two factor interaction

The quality of the models (Table 3 ) was statistically evaluated firstly based on the coefficient of determination $\left(R^{2}\right)$ and by graphical comparison of the predicted vs. measured values (Figure 2).

Table 3. Models summary statistics

\begin{tabular}{|l|l|l|l|l|l|}
\hline \multicolumn{1}{|c|}{ Model } & $\begin{array}{c}\text { Standard } \\
\text { deviation }\end{array}$ & \multicolumn{1}{|c|}{$\mathbf{R}^{\mathbf{2}}$} & Adjusted R $^{\mathbf{2}}$ & Predicted R $^{\mathbf{2}}$ & \multicolumn{1}{|c|}{ PRESS $^{*}$} \\
\hline Linear & 10.68867 & 0.67416 & 0.666698 & 0.650026 & 16074.99 \\
\hline Quadratic & 4.016374 & 0.9561 & 0.952939 & 0.946682 & 2448.981 \\
\hline Cubic & 1.781625 & 0.991984 & 0.99074 & 0.988706 & 518.758 \\
\hline
\end{tabular}

${ }^{*}$ PRESS - Predicted residual error sum of square 


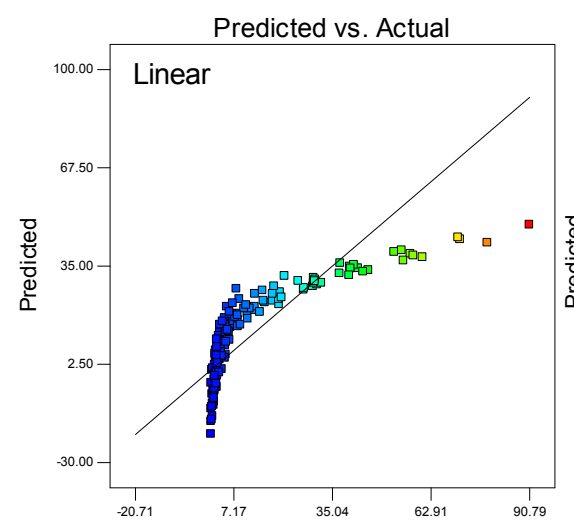

Measured

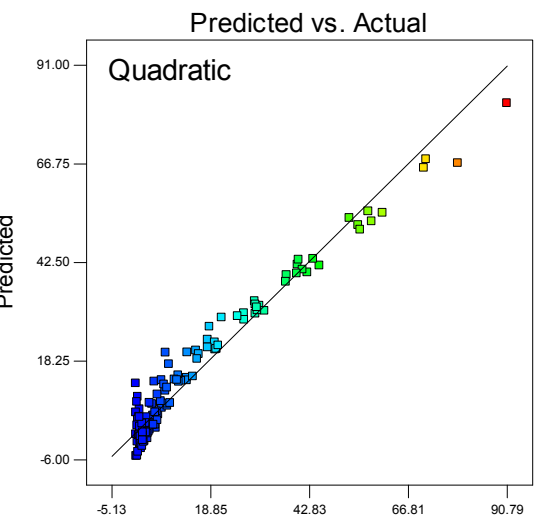

Measured

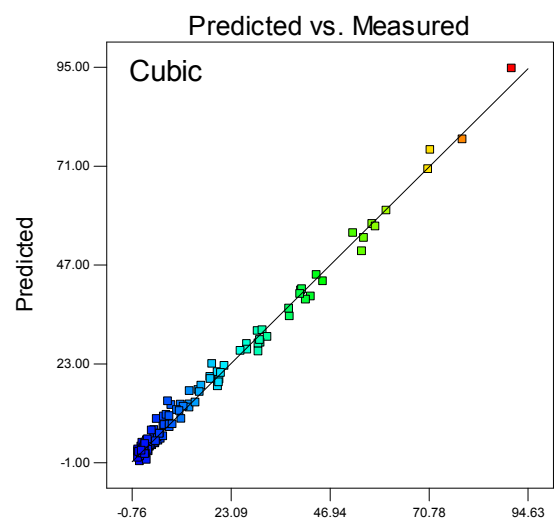

Measured

Figure 2. Plots of measured and predicted values for final CR concentration

$\mathrm{R}^{2}$ is the ratio of the explained variation versus the total variation. It verifies the reliability of an established model. Values of $R^{2}$ closer to 1 will better fit the experimental data while a smaller $\mathrm{R}^{2}$ implies a more reduced similarity between the predicted and the measured records. As noted in Table $3, R^{2}$ is 0.674 for the linear equation, 0.956 for the quadratic model and 0.992 for the cubic one. This means that $32.6 \%, 4.4 \%$ and respectively $0.8 \%$ of the total variables for the analyzed response function were not explained by the models. The adjusted $R^{2}$ value also explains the accuracy of the model. The important difference between $R^{2}$ and adjusted $R^{2}$ is that the latter increases only with the addition of input (independent) variables recognized as significant. If non-significant variables are added into the model, the value of adjusted $R^{2}$ will decrease, whereas the $R^{2}$ will continually 
increase. Thus, the smaller gap between $R^{2}$ and the adjusted $R^{2}$ is desirable for the judgement of a model adequacy. The values of adjusted $R^{2}$ of the response show that only $35.0 \%, 5.3 \%$ and respectively $1.1 \%$ of the total models variation could not explained.

$R^{2}$ values were comparable with those of the predicted $R^{2}$ indicating that the models almost perfectly explain the studied experimental range and they can be successfully used to predict the final dye concentration.

Taking into consideration these aspects, it can be concluded that the linear model is the less precise from all and the cubic model has a slight higher degree of confidence then the quadratic one.

The analysis of variance (ANOVA), detailed in Table 4, shows that the generated mathematical equations models were highly significant, because the F-values are greater than 0.001 . The $p$-values inferior to 0.0001 means that there are only $0.01 \%$ of the total variation that could not be explained by the model and are attributed to the noise signal.

Table 4. ANOVA results of the RSM models

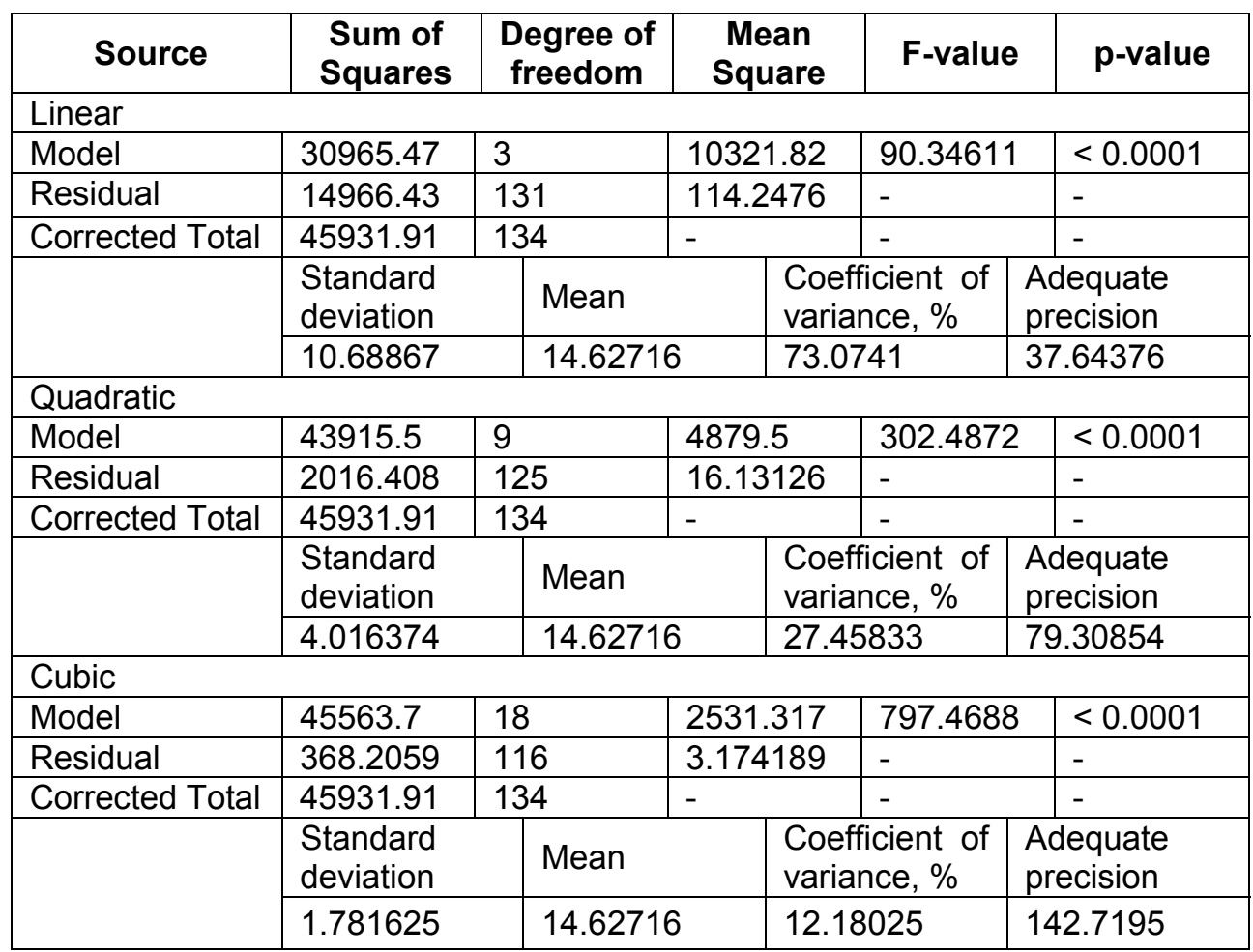


Adequate precision measures the range in predicted response and its associated error (i.e., a signal-to-noise ratio). Its values were higher than 4 implying desirable fitness of the equations. The coefficient of variance (CV) presents the reproducibility of the models. Expressed as the percent ratio between the standard error of the estimate and the mean value of the observed response, when it is under $10 \%$, it states that the model can be considered as reasonably reproducible. The cubic and the quadratic models presented the closest values ( $12.18 \%$ and $27.45 \%$ respectively) to the targeted $10 \%$ of CV while the linear mathematical model has a CV of $73.07 \%$. Therefore, it was not submitted to more advanced statistical analyses.

Table 5 shows the ANOVA of the quadratic model coefficients for the response indicating that eight terms, namely $A, B, C, A B, A C, B C, A^{2}$ and $C^{2}$ were found out to be statistically significant $(p<0.0001)$ for the studied response function. The quadratic term $A^{2}$, was less significant based on a $95 \%$ confidence level $(p<0.05)$. The lowest importance was attributed to the quadratic term $B^{2}(p<0.2488)$.

The sum of squares (SS) of model components was used to calculate the percentage contributions (PC) for each individual term. For the final dye concentration, the time $(C)$ has the highest level of significance with a contribution of $51.29 \%$ as compared to the other components.

Table 5. ANOVA results for the quadratic model coefficients

\begin{tabular}{|c|c|c|c|c|c|c|c|c|}
\hline \multirow{2}{*}{ Factor } & \multirow{2}{*}{$\begin{array}{l}\text { Coeffi- } \\
\text { cient }\end{array}$} & \multicolumn{2}{|c|}{$\begin{array}{c}95 \% \text { Confidence } \\
\text { interval }\end{array}$} & \multirow{2}{*}{$\begin{array}{c}\text { Standard } \\
\text { error }\end{array}$} & \multirow{2}{*}{ F-value } & \multirow{2}{*}{ p-value } & \multirow{2}{*}{$\begin{array}{l}\text { Sum of } \\
\text { squares }\end{array}$} & \multirow{2}{*}{$\begin{array}{c}\text { Contri- } \\
\text { bution } \\
(\%)\end{array}$} \\
\hline & & Low & High & & & & & \\
\hline \multicolumn{9}{|c|}{ Y, Final pollutant concentration } \\
\hline Intercept & 5.523482 & 3.860511 & 7.186453 & 0.840256 & - & - & - & - \\
\hline A & 9.157365 & 8.188344 & 10.12639 & 0.489621 & 349.8013 & $<0.0001$ & 5642.736 & 12.78 \\
\hline B & 5.690574 & 4.851378 & 6.529771 & 0.424024 & 180.1073 & $<0.0001$ & 2905.358 & 6.58 \\
\hline C & $\begin{array}{l}-19.5703 \\
\end{array}$ & -20.6042 & -18.5364 & 0.522412 & 1403.36 & $<0.0001$ & 22637.97 & 51.29 \\
\hline$A B$ & 3.011641 & 1.826688 & 4.196593 & 0.598726 & 25.30174 & $<0.0001$ & 408.1491 & 0.92 \\
\hline$A C$ & -12.5546 & -14.0149 & -11.0943 & 0.737855 & 289.5119 & $<0.0001$ & 4670.192 & 10.58 \\
\hline $\mathrm{BC}$ & -6.83729 & -8.10195 & -5.57263 & 0.639001 & 114.4892 & $<0.0001$ & 1846.856 & 4.18 \\
\hline$A^{2}$ & 1.826601 & 0.191211 & 3.461991 & 0.82632 & 4.886419 & 0.0289 & 78.82412 & 0.18 \\
\hline $\mathrm{B}^{2}$ & -0.84968 & -2.30095 & 0.601582 & 0.733286 & 1.342661 & 0.2488 & 21.65882 & 0.05 \\
\hline$C^{2}$ & 18.24092 & 16.35712 & 20.12471 & 0.951833 & 367.2586 & $<0.0001$ & 5924.346 & 13.42 \\
\hline
\end{tabular}


Table 6 points the ANOVA applied for the cubic model coefficients of the response function indicating that sixteen terms $A, B, C, A B, A C, B C, A^{2}$, $B^{2}, C^{2}, A B C, A^{2} C, A B^{2}, A C^{2}, B^{2} C, B C^{2}$ and $C^{3}$ were found out to be statistically significant $(p<0.0001)$ for the adsorption process. The other terms of the model as the quadratic term $B^{2}$ and his interaction with initial concentrations and time $\left(A^{2} B, A B^{2}, B^{2} C\right)$ and the cubic term $A^{3}$ were highly significant based on a $95 \%$ confidence level $(p<0.05)$, meaning that the variable $p \mathrm{H}$ did not have an intense influence on dye removal in the tested experimental range. For the final dye concentration, the time and his interactions (C) showed the highest level of significance.

Table 6. ANOVA results for the cubic model coefficients

\begin{tabular}{|c|c|c|c|c|c|c|c|c|}
\hline \multirow[t]{2}{*}{ Factor } & \multirow[t]{2}{*}{ Coefficient } & \multicolumn{2}{|c|}{$\begin{array}{c}95 \% \text { Confidence } \\
\text { interval }\end{array}$} & \multirow{2}{*}{$\begin{array}{c}\text { Standard } \\
\text { error }\end{array}$} & \multirow[t]{2}{*}{ F-value } & \multirow[t]{2}{*}{ P-value } & \multirow[t]{2}{*}{$\begin{array}{l}\text { Sum of } \\
\text { squares }\end{array}$} & \multirow{2}{*}{$\begin{array}{c}\text { Contri- } \\
\text { bution } \\
\text { (\%) }\end{array}$} \\
\hline & & Low & High & & & & & \\
\hline \multicolumn{9}{|c|}{$\mathrm{Y}$, Final pollutant concentration } \\
\hline Interc & 4 & 01 & 5.065681 & 6.551948 & - & & 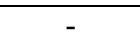 & - \\
\hline A & 34 & 0.766931 & 861 & 061866 & 2.23436 & $<0.0001$ & 65.8017 & 1.02 \\
\hline B & 3.895732 & 0.371286 & 3.160353 & 4.631111 & 110.0932 & $<0.0001$ & 49.4566 & 2.15 \\
\hline C & -15.1419 & 0.776783 & -16.6804 & -13.6034 & 379.9809 & $<0.0001$ & 1206.131 & 7.41 \\
\hline $\mathrm{AB}$ & 2.908154 & 0.266004 & 2.3813 & 3.435008 & 119.5252 & $<0.0001$ & 379.3956 & 2.33 \\
\hline$A C$ & -12.8594 & $\mid 0.327725$ & -13.5085 & \begin{tabular}{|l|}
-12.2103 \\
\end{tabular} & 1539.635 & $<0.0001$ & 4887.093 & 30.04 \\
\hline $\mathrm{BC}$ & -6.94087 & 0.283819 & -7.50301 & -6.37873 & 598.0615 & $<0.0001$ & 1898.36 & 11.67 \\
\hline$A^{2}$ & 1.73932 & 0.36712 & 1.012193 & 2.466447 & 22.44621 & $<0.0001$ & 71.24851 & 0.44 \\
\hline$\overline{B^{2}}$ & 3 & 787 & 32 & 267 & 342 & 0.0158 & 19.04146 & 0.12 \\
\hline $\mathrm{C}^{2}$ & 17.91289 & 0.424883 & 17.07135 & .75442 & 1777.43 & $<0.0001$ & 5641.899 & 34.68 \\
\hline$A B C$ & -2.79414 & 0.400866 & -3.58811 & -2.00018 & 48.58463 & $<0.0001$ & 154.2168 & 0.95 \\
\hline$A^{2} B$ & 0.298217 & 0.448927 & -0.59094 & 1.187374 & 0.441278 & 0.5078 & 1.4007 & 0.01 \\
\hline $\mathrm{A}^{2} \mathrm{C}$ & -2.35658 & 0.553247 & -3.45236 & -1.2608 & 18.14369 & $<0.0001$ & 57.59152 & 0.35 \\
\hline$A B^{2}$ & -1.14011 & 0.460014 & -2.05122 & -0.22899 & 6.142595 & 0.0146 & 19.49776 & 0.12 \\
\hline$\overline{A C^{2}}$ & 10.96966 & 0.597115 & 9.786999 & \begin{tabular}{|l|}
12.15232 \\
\end{tabular} & 337.4976 & $<0.0001$ & 1071.281 & 6.59 \\
\hline $\mathrm{B}^{2} \mathrm{C}$ & 1.397214 & 0.490958 & 0.424809 & 2.369619 & 8.099099 & 0.0052 & 25.70807 & 0.16 \\
\hline $\mathrm{BC}^{2}$ & 3.728796 & 0.517117 & 2.704581 & 4.75301 & 51.99484 & $<0.0001$ & 165.0415 & 1.01 \\
\hline$\overline{A^{3}}$ & -0.54938 & 0.722842 & -1.98106 & \begin{tabular}{|l|}
0.882299 \\
\end{tabular} & 0.577642 & 0.4488 & 1.833547 & 0.01 \\
\hline $\mathrm{C}^{3}$ & -5.6188 & 0.812954 & -7.22896 & -4.00864 & 47.76998 & $<0.0001$ & 151.631 & 0.93 \\
\hline
\end{tabular}


Figures 3 and 4 illustrate the influence of two factors while maintaining the other constant at coded value of 0 for the quadratic and the cubic mathematical models. Dye initial concentration has negative effect on the adsorption process. On the contrary, the $\mathrm{pH}$ showed a positive impact but its influence extent passes from slightly less to highly inferior than that of the adsorption time once that initial dye concentrations increase. The adsorption time is the most important parameter and showed a positive effect on dye removal. The major differences between models are the number of negative values generated on the final dye concentrations, the quadratic model being inferior in the data prediction at low level of initial concentrations and $p \mathrm{H}$ than the cubic one.

Coefficients used for the cubic mathematical model are given in Table 7.

Table 7. Final equation in terms of actual factors

\begin{tabular}{|c|c|c|}
\hline \multicolumn{3}{|c|}{ Final dye concentration $=$} \\
\hline Quadratic coefficients & Cubic coefficients & Actual parameters \\
\hline 4.141866292 & -1.90961894 & - \\
\hline 0.034002923 & 0.016535466 & ${ }^{*}$ Init. dye conc. \\
\hline 5.035463556 & 4.799626589 & ${ }^{*} \mathrm{pH}$ \\
\hline-0.733780548 & -0.089280881 & ${ }^{*}$ Time \\
\hline 0.003011641 & 0.00953296 & ${ }^{*}$ Init. dye conc. ${ }^{*} p \mathrm{H}$ \\
\hline-0.00069748 & -0.001531938 & ${ }^{*}$ Init. dye conc. ${ }^{*}$ Time \\
\hline-0.060775911 & -0.150172977 & ${ }^{*} \mathrm{pH}^{*}$ Time \\
\hline 1.14163E-05 & 4.09688E-05 & ${ }^{*}$ Init. dye conc. ${ }^{2}$ \\
\hline-0.135949235 & -0.12727603 & ${ }^{*} \mathrm{pH}^{2}$ \\
\hline 0.009007859 & 0.00757967 & ${ }^{*}$ Time $^{2}$ \\
\hline- & $-6.2092 \mathrm{E}-05$ & ${ }^{*}$ Init. dye conc. ${ }^{*} p \mathrm{H}^{*}$ Time \\
\hline- & $7.45542 \mathrm{E}-07$ & ${ }^{*}$ Init. dye conc. ${ }^{2 *} p \mathrm{H}$ \\
\hline- & $-3.27303 \mathrm{E}-07$ & ${ }^{*}$ Init. dye conc. ${ }^{2 *}$ Time \\
\hline- & -0.000456044 & ${ }^{*}$ Init. dye conc. ${ }^{*} p \mathrm{H}^{2}$ \\
\hline- & $1.35428 \mathrm{E}-05$ & ${ }^{*}$ Init. dye conc. ${ }^{*}$ Time $^{2}$ \\
\hline- & 0.004967872 & ${ }^{*} \mathrm{pH}^{2 *}$ Time \\
\hline- & 0.000736552 & ${ }^{*} p \mathrm{H}^{*} \mathrm{Time}^{2}$ \\
\hline- & $-8.58406 \mathrm{E}-09$ & ${ }^{*}$ Init. dye conc. ${ }^{3}$ \\
\hline- & $-6.16604 \mathrm{E}-05$ & ${ }^{*}$ Time $^{3}$ \\
\hline
\end{tabular}



STONES ACTIVATED CARBON
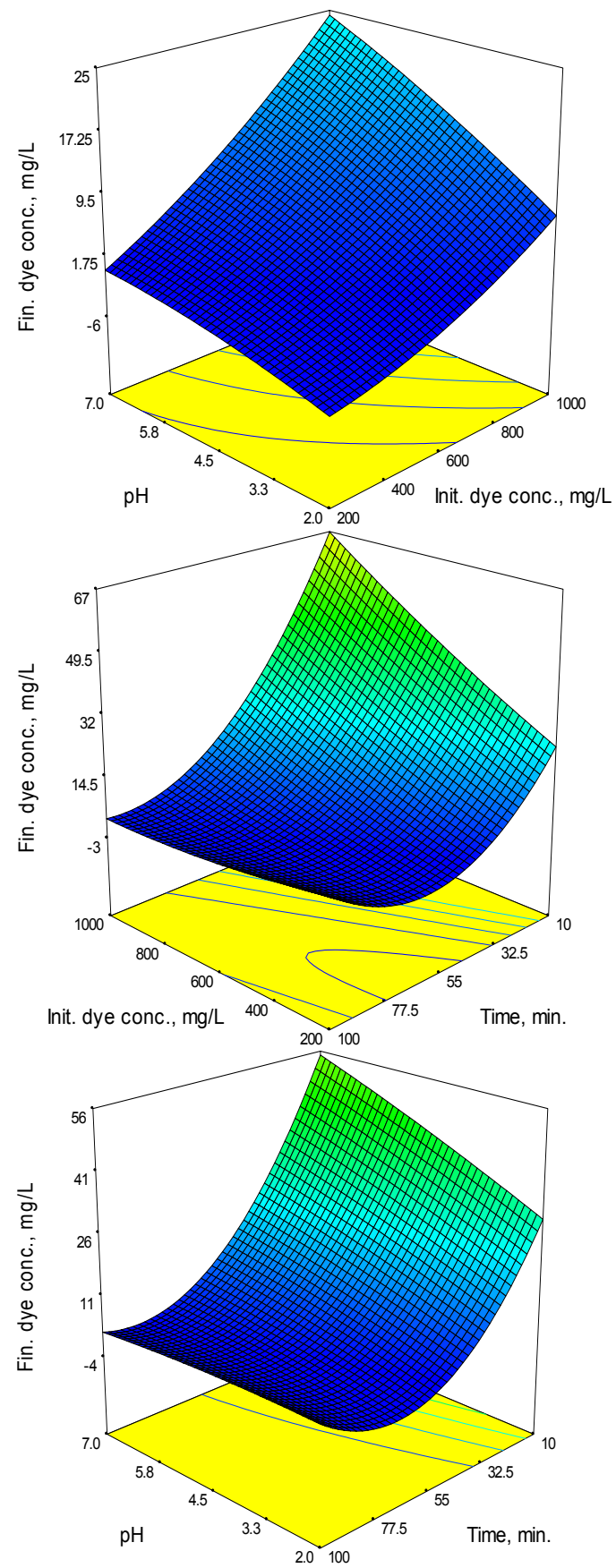

Fin. dye conc., mg/L

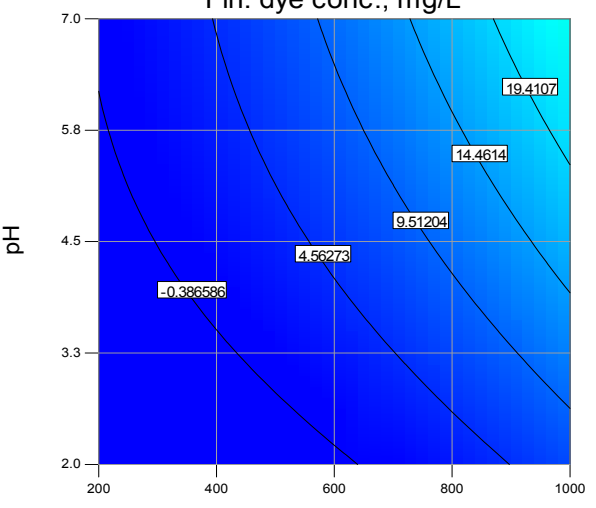

Init. dye conc., $\mathrm{mg} / \mathrm{L}$

Fin. dye conc., mg/L

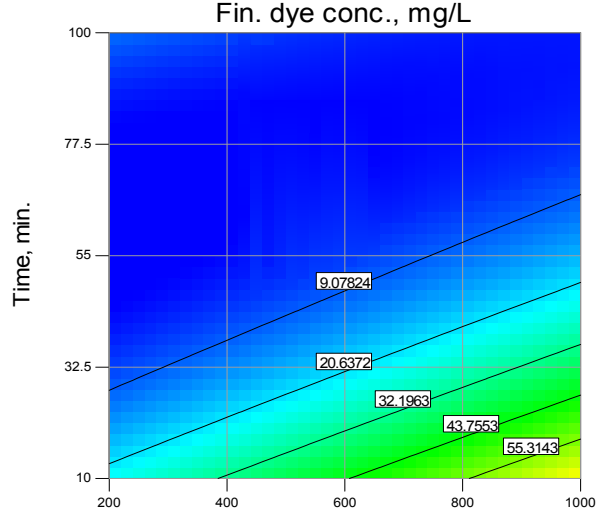

Init. dye conc., mg/L

Fin. dye conc., $\mathrm{mg} / \mathrm{L}$

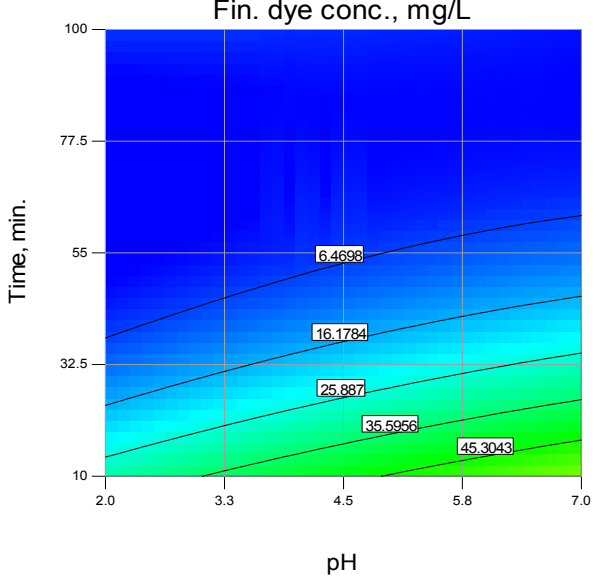

Figure 3. Response surface graphs and contour plots of final dye concentration: the effect of initial dye concentration, $\mathrm{pH}$ and adsorption time for the quadratic model 
ANDREI SIMION, CRISTINA GRIGORAȘ, LIDIA FAVIER, LUCIAN GAVRILĂ
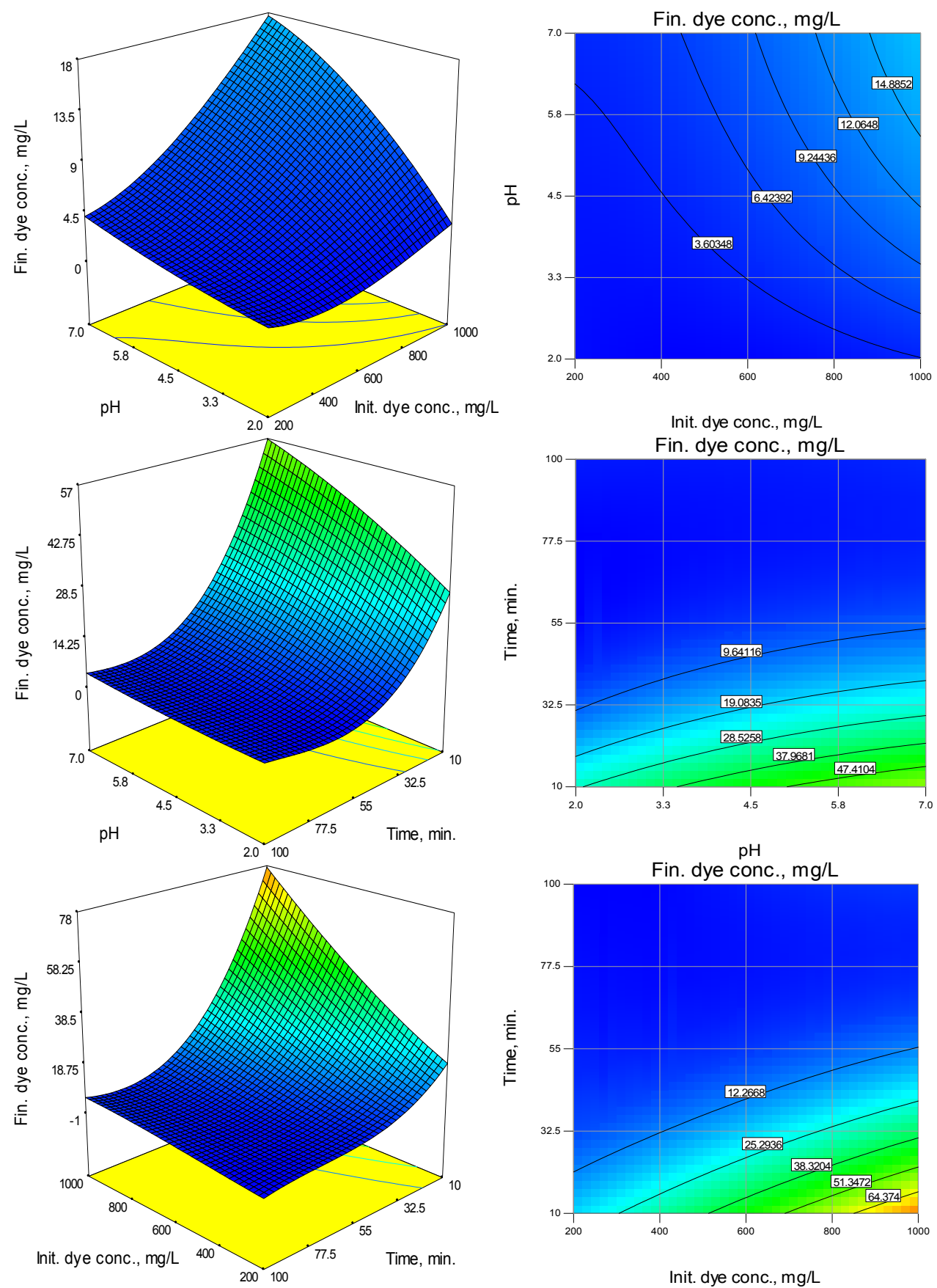

Figure 4. Response surface graphs and contour plots of final dye concentration: effect of initial dye concentration, $\mathrm{pH}$ and adsorption time for the cubic model 
MATHEMATICAL MODELLING AND PREDICTION OF CONGO RED ADSORPTION ON CHERRY STONES ACTIVATED CARBON

\section{Testing the model}

The adopted mathematical model was tested in the conditions planed in the experimental setup A comparison of measured Congo Red final concentrations when dye adsorption from solutions with initial concentrations varying between $200 \mathrm{mg} / \mathrm{L}$ and $1000 \mathrm{mg} / \mathrm{L}$ was conducted at $\mathrm{pH} 4.5$ for 10 to 100 minutes and data predicted by the cubic model is reported in Table 8 as an example. Only minor differences were distinguished. These outcomes along with the similar results registered for runs carried out at $p \mathrm{H} 2.0$ and 7.0 (data not shown) sustain also the model adequacy.

Table 8. Measured final dye concentrations at $p \mathrm{H} 4.5$ vs predicted by cubic model

\begin{tabular}{|c|c|c|c|c|c|c|c|c|c|c|}
\hline \multirow{3}{*}{\begin{tabular}{|c}
$\begin{array}{c}\text { Initial dye } \\
\text { conc. }\end{array}$ \\
$\begin{array}{c}\text { Time } \\
\text { (min) }\end{array}$
\end{tabular}} & \multicolumn{2}{|c|}{$200 \mathrm{mg} / \mathrm{L}$} & \multicolumn{2}{|c|}{$400 \mathrm{mg} / \mathrm{L}$} & \multicolumn{2}{|c|}{$600 \mathrm{mg} / \mathrm{L}$} & \multicolumn{2}{|c|}{$800 \mathrm{mg} / \mathrm{L}$} & \multicolumn{2}{|c|}{$1000 \mathrm{mg} / \mathrm{L}$} \\
\hline & \multicolumn{10}{|c|}{ Final dye concentration, mg/L } \\
\hline & $M$ & $P$ & $M$ & $P$ & $M$ & $P$ & $M$ & $P$ & $M$ & $P$ \\
\hline 10 & 18.177 & 19.756 & 29.580 & 30.889 & 43.797 & 44.482 & 60.602 & 60.124 & 78.919 & 77.401 \\
\hline 20 & 11. & 13.007 & 19.930 & 20.937 & & 31 & 45 & 42 & 57 & 56.269 \\
\hline 30 & 8.3 & 8.238 & 14.616 & 13.508 & 20. & 20.713 & 31.961 & 29.443 & 42. & 39.285 \\
\hline 40 & 5.503 & 5.081 & 9.100 & 8.230 & 13.129 & 13.055 & 20.372 & 19.141 & 25. & 26.078 \\
\hline 55 & 3575 & 3.164 & 4.879 & 4.736 & 6.873 & 7.720 & 10.133 & 11.705 & 13. & 16.279 \\
\hline 60 & 322 & 2.117 & 2.112 & 2.653 & 3 & 4.340 & 4.054 & 6.765 & 5.251 & 9.517 \\
\hline 80 & 1.436 & 1.157 & 1.870 & 1.246 & 2.686 & 1.962 & 3.519 & 2.893 & 4.946 & 3.627 \\
\hline 90 & 1.243 & 0.503 & 1.750 & 1.181 & 2.572 & 2.224 & 3.251 & 3.221 & 4.7 & 3.758 \\
\hline 100 & 1.210 & -0.760 & 1.677 & 1.049 & 2.441 & 2.961 & 3.111 & 4.565 & 4.684 & 5.448 \\
\hline
\end{tabular}

${ }^{*} \mathrm{M}$ - measured value, $\mathrm{P}$ - predicted value

\section{ANN modelling}

A selection of data presented in Table 1 was employed for building a feed forward multilayer perceptron's ANN. The values of the three parameters influencing the adsorption procedure (initial dye concentration, $\mathrm{pH}$ and time) were used as inputs while the final dye concentration was considered as output. The network was trained on $70 \%$ of the input data. The cross validation and the final testing were each managed on $15 \%$ of the inputs. After various trials, a 3 neurons hidden layer with then process elements on the first layer, five process elements on the second and four process elements on the third layer lead to the best results.

At 10000 epochs, the training and the cross validation mean squared errors (MSE) overlay almost perfectly. The MSE insignificant values of 0.000430891 and of 0.000365063 respectively allow to consider that the developed network defines with high confidence the adsorption process evolution. 
The analysis of experimental recorded final dye concentrations and of those predicted by ANN (Table 9) discloses as well no significant dissimilarities. Thus, the chosen ANN can offer a correct fact sustained by the high value of the correlation coefficient $(0.9926)$ and by the low value of the minimum square error (13.61).

Table 9. Measured final dye concentrations vs predicted by ANN model

\begin{tabular}{|c|c|c|c|c|c|}
\hline \multirow{2}{*}{ Run } & \multirow{2}{*}{$\begin{array}{c}\text { Initial dye } \\
\text { concentration, mg/L }\end{array}$} & \multirow{2}{*}{$p \mathrm{H}$} & \multirow{2}{*}{$\begin{array}{l}\text { Time, } \\
\text { min. }\end{array}$} & \multicolumn{2}{|c|}{ Final dye concentration, $\mathrm{mg} / \mathrm{L}$} \\
\hline & & & & Measured & Predicted \\
\hline 1 & 200 & 2 & 10 & 11.172 & 11.196 \\
\hline 2 & 200 & 2 & 20 & 5.858 & 6.949 \\
\hline 3 & 200 & 2 & 40 & 2.022 & 2.785 \\
\hline 4 & 200 & 2 & 50 & 1.075 & 1.021 \\
\hline 5 & 400 & 2 & 30 & 5.448 & 6.869 \\
\hline 6 & 400 & 2 & 90 & 1.083 & 1.147 \\
\hline 7 & 600 & 2 & 60 & 1.896 & 1.467 \\
\hline 8 & 600 & 2 & 80 & 1.728 & 1.446 \\
\hline 9 & 800 & 2 & 50 & 4.911 & 3.771 \\
\hline 10 & 800 & 2 & 60 & 2.435 & 2.040 \\
\hline 11 & 800 & 2 & 80 & 2.045 & 1.861 \\
\hline 12 & 800 & 2 & 90 & 1.85 & 2.183 \\
\hline 13 & 1000 & 2 & 20 & 37.148 & 36.641 \\
\hline 14 & 1000 & 2 & 30 & 18.621 & 20.792 \\
\hline 15 & 1000 & 2 & 50 & 6.012 & 4.550 \\
\hline 16 & 400 & 4.5 & 50 & 4.879 & 4.548 \\
\hline 17 & 400 & 4.5 & 90 & 1.7495 & 2.022 \\
\hline 18 & 800 & 4.5 & 30 & 31.961 & 29.506 \\
\hline 19 & 800 & 4.5 & 40 & 20.372 & 17.766 \\
\hline 20 & 800 & 4.5 & 60 & 4.054 & 5.106 \\
\hline 21 & 1000 & 4.5 & 10 & 78.919 & 69.129 \\
\hline 22 & 1000 & 4.5 & 50 & 13.208 & 12.197 \\
\hline 23 & 1000 & 4.5 & 100 & 4.684 & 4.495 \\
\hline 24 & 200 & 7 & 30 & 11.746 & 12.720 \\
\hline 25 & 400 & 7 & 20 & 30.123 & 29.439 \\
\hline 26 & 400 & 7 & 40 & 13.137 & 12.952 \\
\hline 27 & 400 & 7 & 50 & 8.37 & 7.506 \\
\hline 28 & 600 & 7 & 20 & 40.01 & 42.683 \\
\hline 29 & 600 & 7 & 30 & 30.25 & 30.035 \\
\hline 30 & 600 & 7 & 40 & 20.274 & 19.401 \\
\hline 31 & 600 & 7 & 90 & 3.899 & 3.613 \\
\hline 32 & 800 & 7 & 80 & 5.69 & 4.557 \\
\hline 33 & 1000 & 7 & 10 & 90.788 & 72.717 \\
\hline 34 & 1000 & 7 & 90 & 6.244 & 5.214 \\
\hline
\end{tabular}


Figure 5 shows the measured values versus the predicted responses indicating that the ANN model almost perfectly explains the studied experimental range and can be successfully used to predict the dye final concentration.

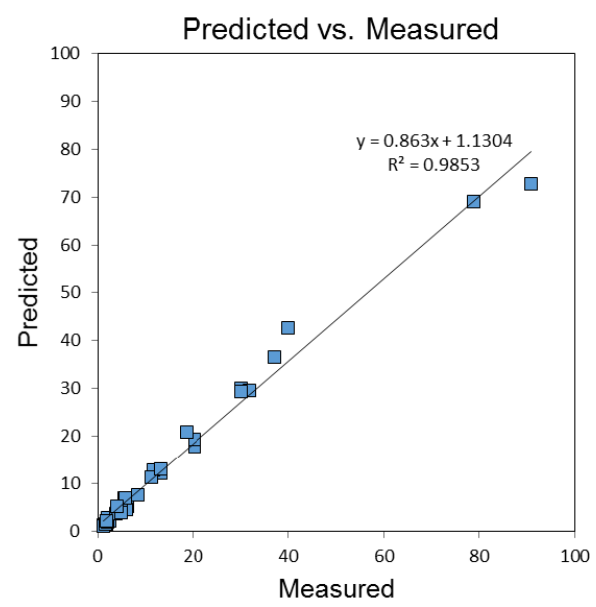

Figure 5. Plot of measured and predicted values for final CR concentration

\section{CONCLUSION}

The present research reveals that Congo Red dye is adsorbed on activated carbon obtained by physical activation method from cherry stones, in acidic and neutral media, more than $99 \%$ of the existing dye being removed after 180 minutes.

Even though there were drawbacks in finding the appropriate mathematical models for describing the adsorption of Congo Red dye when influenced by multiples process parameters, this paper emphasizes the successful possibility of using Response Surface Methodology (RSM) and Artificial Neural Network (ANN) for generate adequate equations that fit the recorded experimental data and illustrate their behavior with a high confidence level.

The third-degree polynomial (cubic) model obtained with RSM can be efficiently employed to predict the residual dye concentrations all over the established parameters ranges: initial concentration from $200 \mathrm{mg} / \mathrm{L}$ to 1000 $\mathrm{mg} / \mathrm{L}, \mathrm{pH}$ from 2 to 7 and contact time between the pollutant and the adsorbent material from 10 minutes to 180 minutes. ANN modelling conducted also to reliable results but contrary to the cubic model, it cannot be emulated in usual computer software's such as Excel spreadsheet requiring only dedicated professional programs which represent a limiting factor for the interested users. 


\section{EXPERIMENTAL SECTION}

\section{Reagents}

Congo Red (CR) dye (Sigma Aldrich, France) solutions with concentrations of $200 \mathrm{mg} / \mathrm{L}, 400 \mathrm{mg} / \mathrm{L}, 600 \mathrm{mg} / \mathrm{L} 800 \mathrm{mg} / \mathrm{L}$ and $1000 \mathrm{mg} / \mathrm{L}$ were obtained with distilled water.

Sodium hydroxide $0.1 \mathrm{~N}$ or hydrochloric acid $0.1 \mathrm{~N}$, procured from Chemical Company (lasi, Romania), were added in order to insure specific $\mathrm{pH}$ values of 2, 4.5, 7, 10 and 12 .

\section{Adsorbent preparation}

Cherry stones used for the adsorbent material preparation were firstly washed then dried at room temperature and crushed.

The resulted powder was calcinated at $600{ }^{\circ} \mathrm{C}$ for $4 \mathrm{~h}$ in a Caloris L1003 laboratory furnace (Caloris Group, Romania) and the product (abbreviated as CS) was kept at $20^{\circ} \mathrm{C}$ in closed vessels until further use.

\section{Adsorption setup}

$0.1 \mathrm{~g}$ of CS were introduced in $50 \mathrm{~mL}$ Erlenmeyer flasks. $20.0 \mathrm{~mL}$ of CR solution having the anteriorly mentioned concentrations and $\mathrm{pH}$ were added.

The adsorption experiments were executed at room temperature on Nahita Blue 692 heating plates (Auxilab, Spain) for 10, 20, 30, 40, 55, 60, 80, $90,100,120,150$ and 180 minutes.

The solid phase was eliminated with the help of a Nahita 2615/1 digital centrifuge (Auxilab, Spain) set at 3000 rpm for 5 minutes.

The CR concentration was determined by UV-VIS spectrometry (Zuzi 4201 UV-VIS spectrophotometer, Auxilab, Spain) at specific maximum absorbance wavelengths $(570 \mathrm{~nm}$ for $p \mathrm{H} 2 ; 530 \mathrm{~nm}$ for $p \mathrm{H} 4.5$ and $500 \mathrm{~nm}$ for $\mathrm{pH}$ 7, 10 and 12).

The adsorption efficiency was calculated with the equation (4):

$$
\text { Adsorption efficiency }(\%)=\frac{C_{0}-C_{e}}{C_{0}} \times 100
$$

where $\mathrm{C}_{0}$ and $\mathrm{C}_{\mathrm{e}}$ are the initial and final dye concentration, respectively.

\section{RSM modelling}

All data recorded from the experimental program were introduced in two computer software's with the special aim of finding mathematical models able to describe the adsorption process. 
Response Surface Methodology (RSM) with custom central composite design (CCCD) based on a three factors and three levels of variation setup was performed using Design-Expert 7.0 software. The regression procedure fitted the polynomial models represented by the equations (5), (6) and (7).

$$
\text { Linear } \quad Y=\beta_{0}+\sum_{i=1}^{k} \beta_{i} X_{i}+e_{0}(5)
$$

Quadratic $Y=\beta_{0}+\sum_{i=1}^{k} \beta_{i} X_{i}+\sum_{i=1}^{k} \beta_{i i} X_{i}^{2}+\sum_{i=1}^{k} \sum_{j=i+1}^{k} \beta_{i j} X_{i} X_{j}+e_{0}(6)$

Cubic

$$
\begin{aligned}
& Y=\beta_{0}+\sum_{i=1}^{k} \beta_{i} X_{i}+ \\
& \sum_{i=1}^{k} \beta_{i i} X_{i}^{2}+\sum_{i=1}^{k} \beta_{i i i} X_{i}^{3}+\sum_{i=1}^{k} \sum_{j=i+1}^{k} \beta_{i j} X_{i} X_{j}+ \\
& \sum_{i=1}^{k} \sum_{j=i+1}^{k} \beta_{i i j} X_{i}^{2} X_{j}++\sum_{i=1}^{k} \sum_{j=i+1}^{k} \beta_{i j j} X_{i} X_{j}^{2}+ \\
& \sum_{i=1}^{k} \sum_{j=1+1}^{k} \sum_{j=i+1}^{k} \beta_{i j k} X_{i} X_{j} X_{k}+e_{0}(7)
\end{aligned}
$$

Herein, $Y$ is the predicted response (final dye concentration); $X_{i}$ and $X_{j}$ are variables; $\beta_{0}$ is the constant coefficient; $\beta_{i}$ is the coefficient that determines the influence of parameter $i$ in the response (linear term), $\beta_{i j}, \beta_{i j k}$, $\beta_{i j}, \beta_{i j}$ are the cross-products, coefficient $\beta_{i i}$ is the quadratic coefficient and $\beta_{i i i}$ is the cubic coefficient, which refer to the effects of the interaction among independent variables. The multiple regression analysis can be applied to obtain the coefficient, and the equation can be used to predict the response.

The coded values (Table 9) of the parameters can be determined from the following equation:

$$
x_{i}=\frac{X_{i}-X_{o}}{\delta X}(8)
$$

$X_{0}$ is the real value of the independent variable at the center point, $X_{i}$ is the real value of the independent variable, and $\delta X$ is the step change values between low $(-1)$ and high (+1) levels.

Table 9. Experimental ranges and levels of the independent test variables

\begin{tabular}{|c|c|c|c|c|c|}
\hline \multirow{2}{*}{ Variables } & \multirow{2}{*}{ Unit } & \multirow{2}{*}{ Symbol } & \multicolumn{3}{|c|}{ Coded variable level } \\
\cline { 4 - 6 } & & & -1 & 0 & 1 \\
\hline Initial dye concentration & $\mathrm{mg} / \mathrm{L}$ & $\mathrm{A}$ & 400 & 600 & 800 \\
\hline$p \mathrm{H}$ & - & $\mathrm{B}$ & 2.0 & 4.5 & 7.0 \\
\hline Time & min. & $\mathrm{C}$ & 10 & 55 & 100 \\
\hline
\end{tabular}




\section{ANN modelling}

Data employed for the Response Surface Methodology design were chosen as inputs and outputs in an Artificial Neural Network three-layered feed forward momentum type. Hidden layers with two to twelve neurons were tried with NeuroSolutions 6.0 software. Three input and one output node with 10000 epochs were used for ANN training.

\section{REFERENCES}

1. N. Ribeiro de Mattos; C. Rodrigues de Oliveira; L.G. Brogliato Camargo; R.S. Rocha da Silva; R. Lassarote Lavall; Sep. Purif. Technol., 2019, 209, 806-814

2. H. Park; J.-H. Hwang; J.-S. Han; B.-S. Lee; Y.-B. Kim; K.-M. Joo; M.-S. Choi; S.-A. Cho; B.-H. Kim; K.-M. Lim; Food Chem. Toxicol., 2018, 121, 360-366

3. C. Goebel; T.L. Diepgen; B. Blomeke; A.A. Gaspari; A. Schnuch; A. Fuchs; K. Schlotmann; M. Krasteva; I. Kimber; Regul. Toxicol. Pharm., 2018, 95, 124-132

4. K.B. Tan; M. Vakili; B.A. Horri; P.E. Poh; A.Z. Abdullah; B. Salamatinia; Sep. Purif. Technol., 2015, 150, 229-242

5. Y. Gao; S.-Q. Deng; X. Jin; S.-L. Cai; S.-R. Zheng; W.-G. Zhang; Chem. Eng. J., 2019, 357, 129-139

6. D. Jiang; M. Chen; H. Wang; G. Zeng; D. Huang; M. Cheng; Y. Liu; W. Xue; Z. Wang; Coordin. Chem. Rev., 2019, 380, 471-483

7. Z. Jia; Z. Li; T. Ni; Z. Li; J. Mol. Liq., 2017, 229, 285-292

8. A. Oussalah; A. Boukerroui; A. Aichour; B. Djellouli; Int. J. Biol. Macromol., 2019, 124, 854-862

9. G.L. Dotto; J.M.N. Santos; E.H. Tanabe; D.A. Bertuol; E.L. Foletto; E.C. Lima; F.A. Pavan; J. Clean. Prod., 2017, 144, 120-129

10. H. Ma; A. Kong; Y. Li; B. He; Y. Song; J. Li; J. Clean. Prod., 2019, 214, 89-94

11. I. Chaari; E. Fakhfakh; M. Medhioub; F. Jamoussi; J. Mol. Struct., 2019, 1179, 672-677

12. W. Hamza; N. Dammak; H.B. Hadjltaief; M. Eloussaief; M. Benzina; Ecotox. Environ. Safe., 2018, 163, 365-371

13. M. Tanzifi; M.T. Yaraki; M. Karami; S. Karimi; A.D. Kiadehi; K. Karimipour; S. Wang; J. Colloid. Interf. Sci., 2018, 519, 154-173

14. A.M. Herrera-Gonzalez; M. Caldera-Villalobos; A.-A. Pelaez-Cid; J. Environ. Manage., 2019, 234, 237-244

15. D.P. Dutta; S. Nath; J. Mol. Liq., 2018, 269, 140-151

16. J. Mo; O. Yang; N. Zhang; W. Zhang; Y. Zheng; Z. Zhang; J. Environ. Manage., 2018, 227, 395-405

17. K.A. Adegoke; O.S. Bello; Water Res. Ind., 2015, 12, 8-24

18. K.H. Toumi; M. Bergaoui; M. Khalfaoui; Y. Benguerba; A. Erto; G.L. Dotto; A. Amrane; S. Nacef; B. Ernst; J. Mol. Liq., 2018, 271, 40-50 
19. M. Wakkel; B. Khiari; F. Zagrouba; J. Taiwan. Inst. Chem. E., 2019, 96, 439-452

20. N.K. Soliman; A.F. Moustafa; A.A. Aoud; K.S.A. Halim; J. Mater. Res. Technol., 2018, https://doi.org/10.1016/j.jmrt.2018.12.010

21. X. Wen; H. Liu; L. Zhang; J. Zhang; C. Fu; X. Shi; X. Chen; E. Mijowska; M.-J. Chen; D.-Y. Wang; Bioresource Tehnol., 2019, 272, 92-98

22. S. Dawwod; T.K. Sen; J. Chem. Proc. Eng., 2014, 1, 1-11

23. T. Ngulube; J.R. Gumbo; V. Masindi; A. Maity; J. Environ. Manage., 2017, 191, 35-57

24. K. Vikrant; B.S. Giri; N. Raza; K. Roy; K.-H. Kin; B.N. Rai; R.S. Singh; Bioresource Technol., 2018, 253, 355-367

25. M.C. Collivignarelli; A. Abba; M.C. Miino; S. Damiani; J. Environ. Manage., 2019, 236, 727-745

26. E. Li; B. Mu; Y. Yang; Bioresource Technol., 2019, 277, 157-170

27. H.N. Tran; S.-J. You; A. Hosseini-Badegharaei; H.-P. Chao; Water Res., 2017, 120, 88-116

28. C.X.-H. Su; L.W. Low; T.T. Teng; Y.S. Wong; J. Environ. Chem. Eng., 2016, 4, 3618-3631.

29. M.M. Hassan; C.M. Carr; Chemosphere, 2018, 209, 201-219

30. C.R. Holkar; A.J. Jadhav; D.V. Pinjari; N.M. Mahamuni; A.B. Pandit; J. Environ. Manage., 2016, 182, 351-366

31. L.Y. Jun; L.S. Yon; N.M. Mubarak; C.H. Bing; S. Pan; M.K. Danquah; E.C. Abdullah; M. Khalid; J. Environ. Chem. Eng., 2019, 7, 1-14

32. M.A. Abdel-Fatah; Ain Shams Eng. J., 2018, 9, 3077-3092

33. M.-H. Zhang; H. Dong; L. Zhao; D.-E. Wang; D. Meng; Sci. Total Environ., 2019, $670,110-121$

34. A. Talaiekhozani, S. Rezania; J. Water Process Eng., 2017, 19, 312-321

35. P.K. Gautam; A. Singh; K. Misra; A.K. Sahoo; S.K. Samanta; J. Environ. Manage., 2019, 231, 734-748

36. S. Karimifard; M.R.A. Moghaddam; Sci. Total Environ., 2018, 640-641, 772-797

37. S. Khamparia; D. Jaspal; J. Environ. Manage., 2017, 201, 316-326

38. A.K.S. Priya; B.S. Kaith; N. Sharma; J.K. Bhatia; V. Tanwar; S. Panchal; S. Bajaj; Int. J. of. Biol. Macromol., 2019, 124, 331-345

39. A.M. Ghaedi; A. Vafaei; Adv. Colloid Interfac., 2017, 245, 20-39

40. M.R. Gadekar; M.M. Ahammed; J. Environ. Manage., 2019, 231, 241-248

41. A. Simion; C.G. Grigoraş; A. Chiriac; N.C. Tâmpu; L. Gavrilă; Environ. Eng. Manag. J., 2018, 17, 771-781

42. A.I. Simion; I. Ioniţă; C.G. Grigoraş; L. Favier-Teodorescu; L. Gavrilă; Environ. Eng. Manag. J., 2015, 14, 277-288

43. S. Kaur; S. Rani; K. Mahajan; J. Chem., 2013, http://dx.doi.org/10.1155/2013/628582

44. C. Tian; C. Feng; M. Wei; Y. Wu; Chemosphere, 2018, 208, 476-483 
